\title{
State of Places on Chronic Diseases in the Ouémé Department in Benin in 2018
}

\author{
Tévoédjrè Doréana Frida ${ }^{1, *}$, Ouendo Edgard-Marius Dona ${ }^{2}$, Gouthon Polycarpe ${ }^{1}$, Mongbo Virginie ${ }^{2}$, Nouatin \\ Kocou Basile', Bio Nigan Issiako', Gouthon Gilchrist Fabrice'
}

\section{Tévoédjrè Doréana Frida ${ }^{1, *}$, Ouendo Edgard- Marius Dona², Gouthon Polycarpe ${ }^{1}$, Mongbo Virginie $^{2}$, Nouatin Kocou Basile', Bio Nigan Issiako, Gouthon Gilchrist Fabrice ${ }^{1}$ ${ }^{1}$ National Institute of Youth, Physical Education and Sport, University of Abomey-Calavi, Cotonou, BENIN. ${ }^{2}$ Regional Institute of Public Health, University of Abomey-Calavi, Ouidah, BENIN.}

\section{Correspondence}

Mrs. Tévoédjrè Doréana Frida

National Institute of Youth, Physical Education and Sport, Sports Performance Research, Health and Evaluation Unit, University of Abomey-Calavi, 169 PortoNovo, Cotonou, BENIN.

Mobile no: +22966313595

Email: tevoedjredoreana@yahoo.fr

History

- Submission Date: 09-09-2019;

- Revised Date: 12-10-2019;

- Accepted Date: 20-11-2019;

DOI : 10.5530/ijmedph.2019.4.30

Article Available online

http://www.ijmedph.org/v9/i4

\section{Copyright}

(C) 2019 Phcog.Net. This is an openaccess article distributed under the terms of the Creative Commons Attribution 4.0 International license.

\begin{abstract}
Context: Chronic disease, a global burden, puts patients in increased and prolonged need of care. Adequate and reliable information on chronic diseases is necessary for the implementation of health policies. Aim: The aim is to study the epidemiological characteristics of chronic diseases that exist in Benin and the Ouémé department and to compare the prevalence of chronic diseases identified in urban areas with those of the rural areas in this department. Settings and design: This is a comparative cross-sectional study. Materials and Methods: The study was conducted using a chronic disease identification sheet, the Delphi method, interview and analysis of consultation records. Statistical analysis used: The data collected with the questionnaire were processed with the SPSS software (IBM, version 21.0). The information collected during the interviews was processed by content analysis in three parts: information condensation, coding, analysis and interpretation of the results. Results: The study participants were active, married and aged 31 to 60 . High blood pressure, diabetes, sickle cell disease, SS and SC, peptic ulcer disease, hepatitis B and C, sinusitis, asthma and AIDS have been identified, both in urban and rural areas. Considering the eight identical diseases in both settings, the highest prevalence in urban areas is diabetes, while, hypertension in rural areas. The lowest prevalence is that of AIDS, whether in urban or rural areas. Conclusion: The data from this study constitute a database for the definition of policies and strategies for the management of people with chronic diseases. Key words: Health policy, Rural environment, Urban environment, Communicable disease, Non-communicable disease.

Key messages: Chronic diseases in rural areas are identical to those in urban areas. The only difference is that in urban areas, rheumatic diseases exist. The lack of infrastructure and qualified personnel does not allow rheumatology consultations to be recorded in rural areas.
\end{abstract}

\section{INTRODUCTION}

A chronic disease considered as a health problem that requires continuous management for years or even decades ${ }^{1}$ because of their prevalence and high involvement in health expenditure. ${ }^{2}$ For defining health policies, it is necessary to know the distribution of the main chronic diseases in the population. The objectives were therefore to identify chronic diseases in the Republic of Benin and in the Ouémé department, identify people with chronic diseases in this department, determine the epidemiological profile of people with chronic diseases and compare the prevalence of chronic diseases identified in urban areas with those in rural areas in this department.

\section{SUBJECTS AND METHODS}

This is a comparative cross-sectional study, carried out from September 2018 to March 2019, in the form of a survey in the Ouémé department of the Republic of Benin. The survey was conducted using a four-step approach. First, the experts' technique was used, then an interview. Then a documentary analysis of the

registers was carried out. Finally, a questionnaire was administered. The study population was subdivided into three groups. A primary target group of people with chronic diseases. The secondary target is general practitioners or specialists working in the health centres chosen for this study. Finally, the tertiary target contained patient consultation registers.

The expert technique was used to identify chronic diseases in Benin. A sample of 22 general practitioners and specialists was selected by this technique in order to implement the Delphi method. For the identification of chronic diseases in the Ouémé department, six doctors selected by the reasoned choice technique because they were the right people to provide the information sought, were interviewed. A literature review of the registers was conducted to identify people with chronic diseases in this department. Two medical centres, one in rural areas and the other in urban areas, were chosen by the simple random technique from those of the Ouémé department. A
Cite this article : Frida TD, Dona OE-M, Polycarpe G, Virginie M, Basile NK, Issiako BN, Fabrice GG. State of Places on Chronic Diseases in the Ouémé Department in Benin in 2018. Int J Med Public Health. 2019;9(4):141-4. 
total of 28 patient consultation registers were studied, 15 in urban areas and 13 in rural areas.

The literature review also estimated the number of cases per identified chronic disease and then the total number of staff in the internal medicine department was read from urban and rural health statistics. These data made it possible to calculate the prevalence of chronic diseases and compare results from urban to rural areas. The questionnaire was used to collect information on the identification of people with chronic diseases in order to establish their epidemiological profile. Initially, a list of 30 people with chronic diseases was established. This list was then used to identify other patients, using the snowball technique, in order to finally constitute a sample of 523 people.

The expert technique as used consisted of two parts: ${ }^{3}$ the expert selection procedure and the questionnaire administration process. According to the Delphi method, a disease has been considered chronic, if $80 \%$ of experts choose it. After the first round was counted, an additional list of diseases was added by the experts. The list resulting from the consensus was provided to them to establish the classification based on the frequency of consultation of chronic diseases.

The interview was conducted with an interview guide consisting of four main questions and three other follow-up questions. The interviews were conducted individually in the selected hospitals, according to a schedule agreed with the doctors. A commitment has been made to destroy the recordings, no later than six months after their exploitation.

The registers were consulted to estimate the prevalence of the identified chronic diseases and compare data from urban and rural areas. The questionnaire used included 8 questions on patient identification.

All measures have been taken to ensure anonymity and confidentiality of data collected from people with chronic diseases. All the patients selected gave their informed and verbal consent to participate in the study, for which the approval of the Scientific Committee on Science and Technology of Physical and Socio-Educational Activities of the University of Abomey-Calavi was previously required.

The data collected with the questionnaire were processed with the SPSS software (IBM, version 21.0). The information collected during the interviews was processed by content analysis in three parts: information condensation, coding, analysis and interpretation of the results. ${ }^{4}$

\section{RESULTS}

\section{For the Delphi method}

Among the 22 experts who participated in the application phase of this method, there were 11 general practitioners and 11 specialists with 8 to 17 years of practice. A total of 133 chronic diseases have been identified in Benin. They have been distributed as follows: respiratory and ENT diseases with 15 conditions; hematological diseases with 14 conditions; heart and vascular diseases with 12 conditions; diseases of the digestive system with 11 conditions; neurological and muscular diseases with 11 conditions; renal, urinary or genital diseases with 11 conditions; cancers with nine different forms; endocrine diseases with nine conditions; eye diseases with nine conditions; skin diseases with nine conditions; rheumatological diseases with eight conditions; psychiatric and psychological diseases with seven conditions; chronic infectious diseases with five conditions; systemic diseases with three conditions.

\section{Data from the interview}

With respect to the identification of chronic diseases in rural areas, Doctor A expresses himself by saying "good good good good... here the types of chronic diseases I encounter here. I can mention high blood pressure or hypertension, type 2 diabetes, ulcers, hepatitis, sinusitis, sickle cell disease, asthma". Doctor M points out that in addition to the diseases mentioned above, there is another one:"... I would say that as far as these diseases are concerned, there is also AIDS". Chronic diseases identified in rural areas include high blood pressure or hypertension, type 2 diabetes, peptic ulcer disease, hepatitis B and C, sinusitis, sickle cell disease in its SS and SC forms, asthma and AIDS. In the urban environment, Doctor S in his remarks stated "I mainly treat diabetes but in addition, I am a general practitioner so let's say I can mention hypertension... I think there is also asthma, sinusitis". Doctor Ab confirms and completes this list by saying "I can list diabetes, hypertension, sinusitis, asthma, sickle cell disease, hepatitis, ulcers, $H I V$ ". Chronic diseases in rural areas are identical to those in urban areas. Doctor $S$ considered that in addition to the various chronic diseases mentioned above, others exist "There are also chronic diseases related to rheumatology but only the rheumatologist can list them for you". The only difference is that in urban areas, rheumatic diseases exist.

\section{Data from the analysis of the registers}

The highest prevalence in urban areas was that of diabetes (Table 1) versus hypertension in rural areas, with no significant difference between the two values $(6.3 \%$ versus $2.2 \% ; p=0.11)$. The lowest prevalence was that of AIDS, whether in urban or rural areas, with no significant difference between the two values $(0.04 \%$ versus $0.05 \%$; $p=0.95)$. Regardless of the disease, there was no difference between the prevalence observed in urban and rural areas $(p>0.05)$.

\section{Data from the questionnaire}

High blood pressure has the highest number of people, regardless of gender, status and occupational category, marital status except at the age category level, for which the highest number concerns diabetes. The 31 to 60 age group contained the largest number of patients, more than $50 \%$ of whom are working, married and in the professions (Table 2).

\section{DISCUSSION}

The chronic diseases identified in the Ouémé department are the same in urban areas as in rural areas and the majority of people suffering from them are over 30 years old, active and married. It is on the basis of this assumption that this study was carried out, using a multi-step approach. The Delphi method was first used to gather, through an open-ended questionnaire, the justified opinion of a panel of experts from different medical specialties. The participation of the experts solicited was very good, with a $100 \%$ response rate for each round of the Delphi process. However, the fact that the determination of the epidemiological profile of people with chronic diseases did not take into account the economic and dietary aspects that could help to better understand comparative results between urban and rural areas could be a limitation of this study.

\begin{tabular}{|c|c|c|c|}
\hline Chronic diseases & $(n=260)$ & Rural & $\begin{array}{l}\text { Urban p } \\
\qquad(n=732)\end{array}$ \\
\hline - High blood pressure & 2,28 & 4,33 & $0,1(2,28$ vs 6,34$)$ \\
\hline - Peptic ulcer disease & 1,23 & 0,52 & \\
\hline - Sickle cell disease SS and SC & 1,06 & 0,33 & \\
\hline - Sinusitis & 0,96 & 0,16 & \\
\hline - Hepatitis B and C & 0,56 & 0,16 & \\
\hline - Type 2 diabete & 0,15 & 6,34 & \\
\hline - Asthma & 0,10 & 0,15 & \\
\hline - AIDS & 0,05 & 0,04 & $0,95(0,05$ vs 0,04$)$ \\
\hline
\end{tabular}

Source: Consultation register and health statistics of health centre 


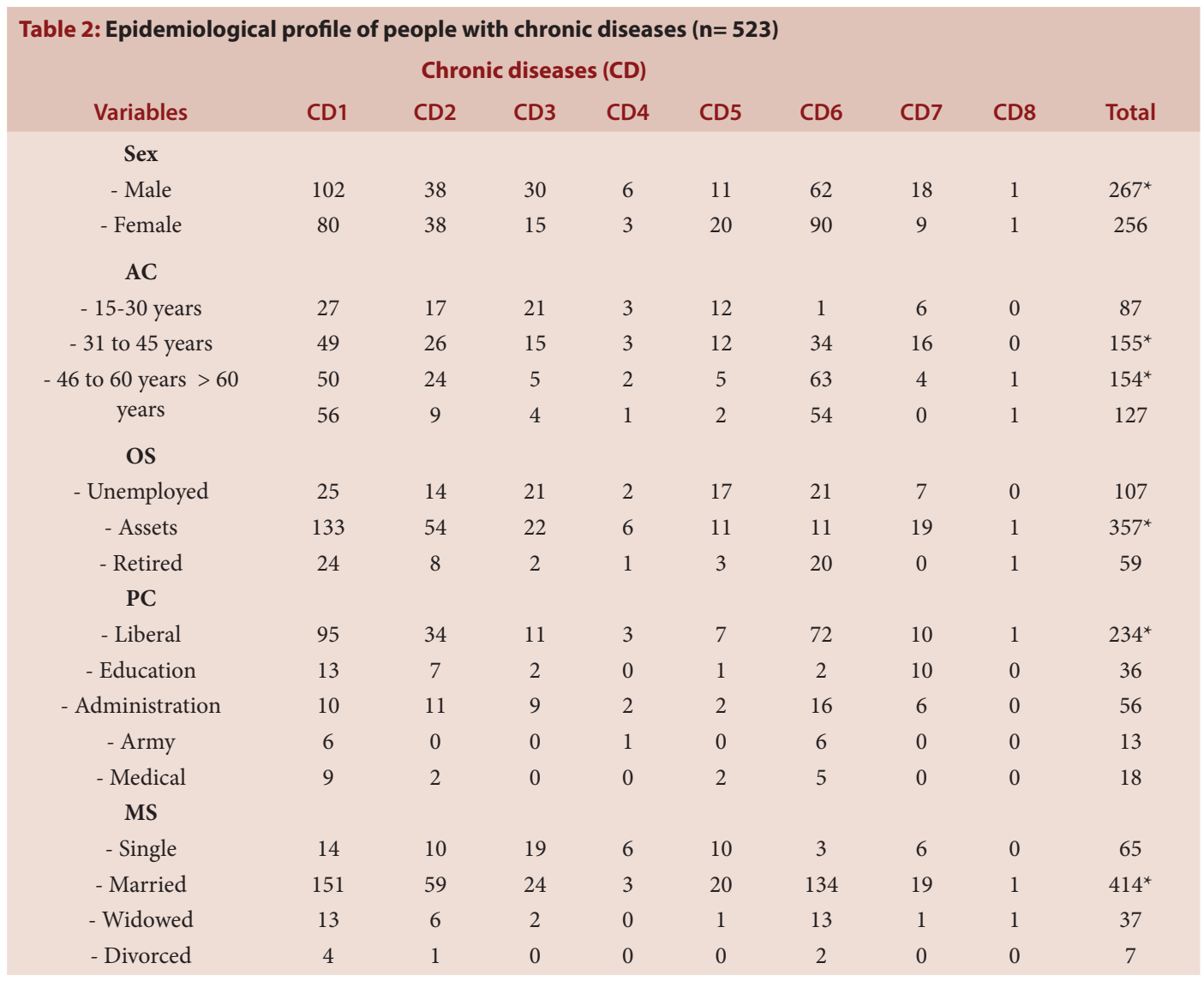

* High number of people by variable; AC: age category; OS: occupational status; PC: professional category; SM: marital status; CD1: High Blood Pressure; CD2: peptic ulcer disease; CD3: sickle cell disease SS and SC; CD4: asthma; CD5: hepatitis B and C; CD6: diabete; CD7: sinusitis; MC8: AIDS

Nevertheless, this research revealed that men suffer from more chronic diseases than women in the study area, i.e. the Ouémé department. In addition, the data collected suggest that males play a role in the occurrence of chronic diseases in this region of Benin. On one hand, men are more likely than women to engage in addictive behaviours that can affect their health and put them at greater risk of developing any of the chronic diseases. ${ }^{5}$ On the other hand, women become more likely to develop asthma because their airways become smaller. ${ }^{6}$ In addition, the age category with the largest number of people with chronic diseases in this study is 31 to 60 years. Age is thus an unmodifiable factor in the development and worsening of chronic diseases in that the prevalence of type 2 diabetes increases with age among both men and women. ${ }^{7}$ The highest number of people in the study was found in the active, married and self-employed category. The available literature data on this subject have not observed this socio-professional characterization of people with chronic diseases. They focused mainly on age groups ${ }^{8}$ and gender. ${ }^{9}$ In this study, eight chronic diseases identical to the two residential settings were identified. These are sinusitis, hypertension, type 2 diabetes, peptic ulcer, hepatitis B and C, sickle cell disease in its SS and SC forms, asthma and AIDS.

With regard to HBP, the prevalence was $23.4 \%$ in rural Senegal but $61.36 \%$ in the city of Bobo-Dioulasso, ${ }^{10}$ and then $31.10 \%$ in Benin in the departments of Borgou and Alibori. ${ }^{11}$ The prevalence obtained in the literature is therefore mostly higher than that of this study. In fact, in the Ouémé department in 2018, in urban areas, it was $4.33 \%$ and $2.28 \%$ in rural areas. For asthma, the reported prevalence was $9.65 \%$ in Cameroon ${ }^{12}$ and 5.4\% in Reunion Island. ${ }^{13}$ In this study, prevalences for asthma were lower, with figures ranging from $0.10 \%$ in rural areas to $0.15 \%$ in urban areas. The prevalence of sickle cell disease varied between 4 and $25 \%$ in Mali. ${ }^{14}$ In the Ouémé department and particularly in hospitals, it was lower with percentages of 1.06 for rural areas and 0.33 for urban areas. The differences observed between the results of this study and those reported in the literature are mainly due to the fact that the prevalence were determined with data from the local population that does not necessarily correspond to the hospital population.

The prevalence of diabetes was $12.9 \%$ in N'Djamena, in an urban hospital setting. ${ }^{15}$ It was estimated at 3\% in 2010 and, two years later, it was around $4.2 \%$ for all departments in Benin. ${ }^{16}$ The prevalence rates obtained in the Ouémé department in 2018 during this study were, therefore, lower, ranging from $0.15 \%$ in rural areas to $6.34 \%$ in urban areas. The prevalence of peptic ulcer disease was $15.53 \%$ at the Lome Campus UHC. ${ }^{17}$ The figures reported are high compared to those of this study, which was $1.23 \%$ in rural areas and $0.52 \%$ in urban areas. This difference is certainly related to the type of study conducted and the duration of data collection. In the literature, this was a five-year retrospective study, while in this study, the cross-sectional approach was used.

The prevalence of hepatitis B was estimated at $13.9 \%$ in Parakou. ${ }^{18}$ At the Abomey-Calavi zone hospital, it was $11.01 \%{ }^{19}$ while the prevalence was $0.56 \%$ lower in rural areas and $0.16 \%$ lower in urban areas in the Ouémé department. These figures are below the values of the literature. This difference can be explained by the fact that the prevalence obtained in the city of Parakou was determined according to serological status at a given time and in Abomey-Calavi, it was determined using data collected over five years. Allergic rhinitis affects 10 to $40 \%$ of the world's population. ${ }^{20}$ 
In this study, the prevalence of this disease was $0.96 \%$ in rural areas and $0.16 \%$ in urban areas. The prevalence, which is lower in this study, is due to the fact that the data were collected in a hospital setting that did not necessarily correspond to that of the entire local population, or even to the world population. In addition, HIV/AIDS prevalence rates were $2.1 \%$ in Togo, $0.4 \%$ in Senegal, $3.7 \%$ in Cameroon and $1.2 \%$ in Benin, with rates ranging from $1.6 \%$ in urban areas to $0.9 \%$ in rural areas. ${ }^{21}$ In the Ouémé department, this prevalence is lower with rates of $0.05 \%$ in rural areas and $0.04 \%$ in urban areas. The difference observed between the prevalences is certainly still related to the data collection environment, as already mentioned for the diseases mentioned above. The initial hypothesis formulated in this study was confirmed by the various data obtained in the Ouémé department. These results, which contribute to a better understanding of the distribution of the main chronic diseases among the population of Benin, can be used to redefine strategies for the management of people suffering from chronic diseases in this country.

\section{CONCLUSION}

The objectives of this study were to identify the chronic diseases present in the Ouémé department and in Benin, estimate the prevalence of the identified chronic diseases and determine the epidemiological profile of people suffering from chronic diseases.

The data collected identified eight diseases, the same in urban and rural areas. These are high blood pressure, diabetes, peptic ulcer, hepatitis B and C, sickle cell disease in its SS and SC forms, sinusitis, asthma and AIDS. The highest prevalence in urban areas is that of diabetes versus hypertension in rural areas. The lowest prevalence is that of AIDS, whether in urban or rural areas. The most affected by these conditions are active, married people between 31 and 60 years of age.

The results of this study can be considered as baseline data on chronic diseases in the Ouémé department, thus allowing comparison with those of populations in previous work. In this perspective, other studies with the same objectives should be carried out in the other departments to provide Benin with a national basis. Such a basis can be used when defining strategies for the management of people with chronic diseases.

\section{ACKNOWLEDGEMENT}

The authors are extremely grateful to all subjects for their valuable time and active participation in the study.

\section{CONFLICT OF INTEREST}

The authors declare no conflict of interest.

\section{ABBREVIATIONS}

HIV: Human Immune Virus; AIDS: Acquired Immuno Deficiency Syndrome; HBP: High Blood Pressure; SS: homozygous; SC: heterozygous.

\section{REFERENCES}

1. WHO. Innovative care for chronic conditions: building blocks. Executive Sum- mary. Geneva (Switzerland). 2003

2. Center for Disease Control and Prevention. Chronic diseases: The power to prevent. The call to control at a glance. 2009. Available at: http://www.cdc.gov/ nccdphp/publications/ AAg/chronic.htm

3. Okoli C, Pawlowski SD. The Delphi method as a research tool: An example, design considerations and applications. Information and Management. 2004;42(1):15-29. doi:10.1016/j.im.2003.11. 002

4. Garden L. Content analysis. University Press Edition of France. Paris. 1977;1234.

5. Carbonneau M. Chronic diseases in Estrie: Risk factors. In: Agency of health and social services of Estria, editor. Direction of Public Health and Evaluation: Sherbrooke. 2007;70.

6. Cragg S, Craig CL. Regional Health Bulletin: Who accumulates the most time in front of a screen?. Canadian Fitness and Lifestyle Institute. Ottawa. 2009;4.

7. Lemire L, Garand C. Risk factors associated with chronic diseases. Chronic diseases in Lanaudiere. Agency of health and social services of Lanaudiere Direction of public health and evaluation. Monitoring, research and evaluation service. Canada. 2010;40

8. Lofandjola JM, Kiswaya SE, Petermans J. Burden of chronical disease in subsharian Africa: A plea for implementation of palliative care and end of life support in Democratic Republic of Congo. Ethics, Medicine and Public Health. 2017;3:374-80. doi: 10.1016/ j.jemep.2017.06.003

9. Vernay M, Bonaldi C, Grémy I. Chronic diseases: Recent trends, challenges and prospects for future development. Public Health. 2015;27(1):189-97.

10. Tougouma SJB, Hien $H$, Aweh AB, Yaméogo AA, Méda ZC, et al. Prevalence and knowledge of hypertension in the elderly: Cross-sectional study conducted in Bobo-Dioulasso, Burkina Faso. PAMJ. 2018;30:243. doi: 10.11604/ pamj.2018.30.243.15997

11. Ahoui S, Vigan J, Agboton BL, Oké P, Houétondji CL, Dovonou CA, et al. High blood pressure and associated factors in the Borgou and Alibori Departments in Benin in 2014. Eur Sci J. 2016;12(33):235-44

12. Massongo D, Adamou V, Poka EW, Yone P. Prevalence and determinants of selfreported asthma in an adult population in urban areas of Cameroon. Review of Respiratory Diseases. 2018;35:A86-7. doi: 10.1016/j.rmr.2017.10.186

13. Solet JL. Chronic respiratory diseases and traumas: Study of the prevalence of asthma in Reunion Island as a general population in 2016. Public Health France. 2018;125.

14. Lainé A, Diallo D, Traoré B. From Koloci to sickle cell disease. Anthropology and Health. 2012;26. [April. online on 31 May 2012]. Available at: http://journals. openedition.org/ anthropologiesante/884

15. Dionadji M, Oumar A, Nodjito M, Ibrahim A. Prevalence of medical complications among diabetics hospitalized in Ndjamena. Health Sci Dis. 2015;16(3):1-4. Available at: www.hsd-fmsb.org

16. Djrolo F, Houinato D, Gbary A, Akoha R, Djigbénoudé O, Sègnon J. Prevalence of diabetes mellitus in the adult population at Cotonou, Benin. Medicine of Metabolic Diseases. 2012;6(2):167-9. doi: MMM-03-2012-6-2-2-1957-2557101019-201200908

17. Lawson-Ananissoh LM, Bouglouga O, Bagny AR, El-Hadj Y, Kaaga L, Redah D. Epidemiological profile of peptic ulcers at the Campus de Lomé hospital and university centre. J Afr Hepatol Gastroenterol. 2015;9(3):99-103.

18. Ariyoh AS, Dovonou CA, Houehanou C, Kpangon A, Ahanhanzo-Glele R, Kpangon JH, et al. Prevalence of chronic hepatitis B by HIV serological status in Parakou, Benin. The PAMJ. 2018;30:180. doi: 10.11604/pamj. 2018.30.180.180.161 17

19. Lozes E, Bankolé HS, Dougnon TV, Baba-Moussa L. Prevalence of HBsAg at Abomey Calavi / Sô-Ava Zone Hospital in Benin from 2009 to 2014. Int J Biol Chem Sci. 2016;10(4):1832-9. doi: 10.4314/ijbcs.v10i4.31

20. Shin JH, Roh D, Lee DH, Kim SW, Kim SW, Cho JH. Allergic rhinitis and rhinosinusitis synergistically compromised the mental health and health-related quality of life of Korean adults: A nationwide population-based survey. PLoS One. 2018;13(1):e0191115. doi: 10.1371/ journal.pone.0191115

21. World Bank. HIV prevalence, total percentage of the population aged 15-49 years. Washington, D.C. (United States). 2017. 